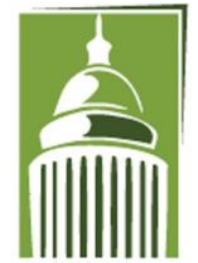

AR F
Global Proceedings Repository

American Research Foundation

ISSN 2476-017X

Available online at http://proceedings.sriweb.org

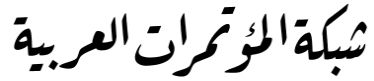

http://arab.kmshare.net/

\title{
Contemporary International Scientific Forum
}

for Educational, Social, Human, Administrative and Natural Sciences

"Present Vs Future Outlook"

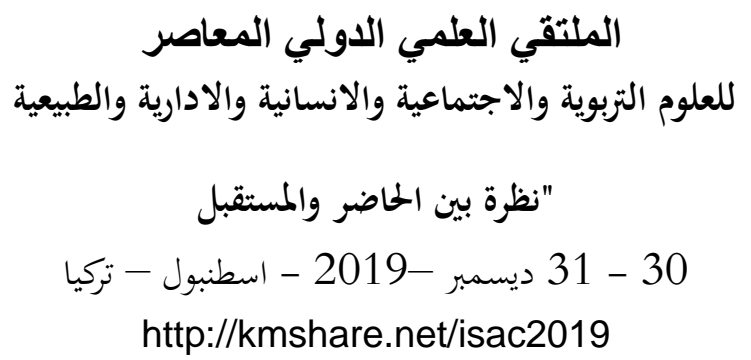

\section{Effectiveness of The Proposed Program in Mathematics Based on Blended Learning in Developing Achievement at Basic School Students in Palestine}

\section{Mirvat M. Sharif}

\section{Teacher/Directorate of Education in Hebron-Palestine}

\begin{abstract}
The objective of current research is to develop Achievement through the teaching of the unit in Mathematics at the basic seventh grade from the upper stage of basic education in Palestine. The research group consists of (40) students, of Al Qwasima school in Hebron government, Twenty (20) of them represent experimental group which study according to Blended Learning based program in Mathematics and the other twenty (20) students represent the control group. The application of program had one month in the second term of the year 2018-2019.

The researcher used the experimental approach and the quasi- experimental design in this study Achievement Test also used. It was applied on the two groups before and after applying the study. The educational material was prepared, according to the program based on Blended Learning.

The result of research: There are significant statistically function differences between mean scores of students in the control group and experimental group in the post application of the inquiry thinking skills test in favor of students of the experimental group. There are significant statistically function differences between mean scores of students in the experimental group which studies according to the proposed program in both pre and post applications of the Achievement test in favor of post application.
\end{abstract}

Key words : Blended Learning, Achievement 


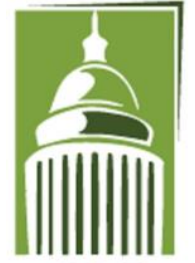

AR F
Global Proceedings Repository

American Research Foundation

ISSN 2476-017X

Available online at http://proceedings.sriweb.org

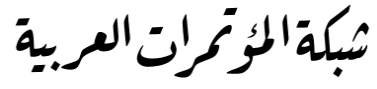

http://arab.kmshare.net/

\section{"فاعلية برنامج مقترح في الرياضيات قائم على التعلم المدمج في تنمية التحصيل لدى طلبة المرحلة الأساسية في فلسطين"

$$
\text { معلمة /مديرية تربية وتعليم الخليل - فلسطين }
$$

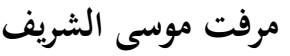

\section{الملخصص}

هدف البحث الحالي إلى تنمية التحصيل في الرياضيات لطلبة الصف السابع الأساسي من مرحلة التعليم الأساسي في فلسطين، وذلك باستخدام برنامج مقترح قائم على التعلم المدمج.

تكونت عينة البحث من (40) طالبة من مدرسة القواسمة الأساسية بمديرية التربية والتعليم بالخليل، وقسمت العينة الى بموعتين تجريبية وضابطة، (20) طالبة مثلت المجموعة التجريبية التي درست وفقاً للبرنامج القائم على التعلم المدمج و و(20) طالبة مثلت المجموعة الضابطة، وقد استغرق تطبيق البرنامج مدة شهر واحد من الفصل الدراسي الثاني لعام 2019/2018م.

استخدمت الباحثة المنهج التجريبي والتصميم شبه التجريب، لملاءمته لأهداف البحث، ومن أجل تحقيق أهدافه، تم إعداد أداة الدراسة وهي: اختبار التحصيل، وتم التحقق من صدق الأداة وثباتها بالطرق المناسبة، وطبقت الأداة على بجموعتي الدراسة (الضابطة، والتجريبية)، قبل البدء بالمعالجة وبعدها، وتم إعداد المادة التعليمية، التي تمثلت ببرنامج تعليمي قائم على التعلم المدمج. وقد خرجت الدراسة بجملة من النتائج وهي: توجد فروق ذات دلالة إحصائية بين متوسطات درجات طالبات المجموعة التجريبية التي تدرس باستخدام البرنامج القائم على التعلم المدمج في اختبار التحصيل الكلي للتطبيقين القبلي و البعدي, لصالح التطبيق البعدي. وتوجد فروق ذات دلالة إحصائية بين متوسطات درجات طالبات المجموعتين الضابطة والتجريبية في اختبار التحصيل

$$
\text { البعدي ككل, لصالح المجموعة التجريبية. }
$$

الكلمات المفتاحية: التعلم المدمج، التحصيل. 


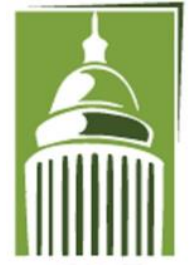

AR F

\section{Global Proceedings Repository}

American Research Foundation

ISSN 2476-017X

Available online at http://proceedings.sriweb.org

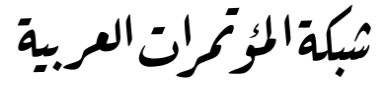

http://arab.kmshare.net/

المقدمة - م

تشهد التربية العلمية وتدريس الرياضيات اهتماماً كبيراً_ محلياً وعربياً وعالمياً_ تطويراً نحو الأفضل لمواكبة خصائص العصر العلمي التكنولوجي والمعلوماتية والاتصالات ومتطلبات القرن الحادي والعشرين وتحدياته الآنية والمستقبلية، حيث نعيش هذه الأيام مرحلة وعصراً علمياً بالغي التقدم, وهذا بدوره قد أدى الى حدوث طفرات هائلة في مجال التصميم وإنتاج برامج الوسائط المتعددة وعرضها من خلال الحاسوب والوسائل الالكترونية.

وشهدت السنوات الأخيرة تطورات كثيرة في مجال التعليم حيث تغيرت العديد من المكونات الرئيسية لعملية التعلم من حيث الشكل والوظيفة، فمن حيث الشكل تغير المحتوى من الشكل التقليدي المطبوع المى الشكل الإلكتروني متعدد الوسائط المعتمد

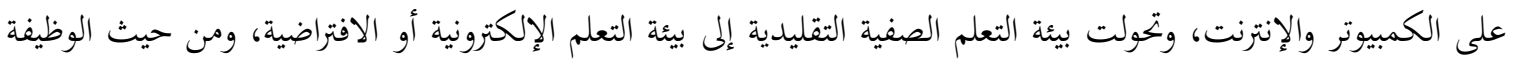
فقد أصبح المعلم له دور المرشد والميسر لطلابه لإنجاز الأنشطة التعليمية وتحقيق الأهداف التعليمية، أما بالنسبة للطالب فأصبح من مستقبل ومتلقي سلبي للمعلومات التي تقدم إليه من المعلم والمحتوى إلى متفاعل إيجابي مع المحتوى ويغلب على دوره النشاط

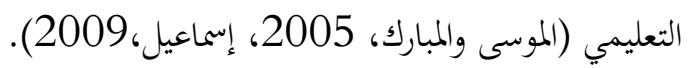

وقد تعددت وتنوعت طرق تدريس الرياضيات وأساليبها وشهدت هذه الطرق و الأساليب تطوراً ملحوظاً بهدف تقديم

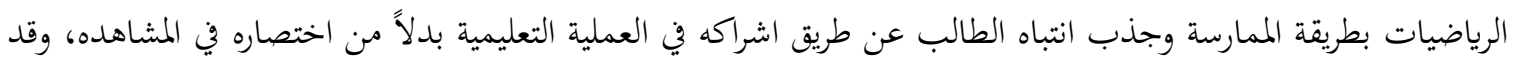
نتج عن هذا التقدم اكتشافات جديدة في مجال تقنية المعلومات والاتصال واتي من أبرز انجازاتا ظهور التعلم الالكتروني. .(2005, Hudson)

ولم يعد يخفى على أحد أثر وأهمية التعلم الإلكتروني وما أضفاه على العملية التعليمية، مما جعله من القضايا الأساسية التي تشغل التربويين المهتمين منهم بمجال تكنولوجيا التعليم، وعلى الرغم من أن ظهور الإنترنت والتعلم الإلكتروبي وتطبيقاته

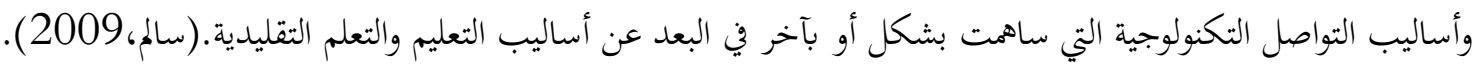




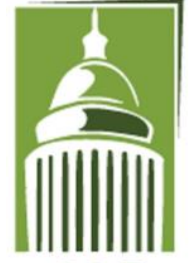

AR F
Global Proceedings Repository

American Research Foundation

ISSN 2476-017X

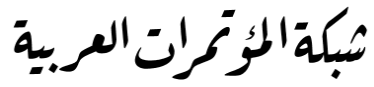

http://arab.kmshare.net/

Available online at http://proceedings.sriweb.org

لهذا شهدت منظومة التعلم الالكتروني بصيغة عامة وتعليم الرياضيات بصفة خاصة, نقلة نوعية حادة كما يشير إلى ذلك سالم(2009), نجمت عن ظهور أنماط تعليمية مستحدثه في الفترة الأخيرة, الهدف منها هو جعل المتعلم محور العملية التعليمية بدلاً من المعلم ومن أشهرها التعلم الالكتروني بكافة أنماطه المختلفة, الذي يتيح للمتعلم التعلم في المكان والزمان المناسبين له دون الحاجة للحضور إلى قاعات الدراسة. ومن هذا المنطلق كانت الحاجة إلى تدخل جديد يجمع بين ميزات كل من التعليم التقليدي و التعلم الالكتروني, والتغلب على جوانب القصور في كل منهما. فأتت الفكرة بضرورة دمجها معاً في توليفة متناسقة, للتخلص من عيوب كل منهما على حدة مما يسمح للمتعلمين بالاستفادة من هاتين الطريقتين في الوقت ذاته والحصول على مخرجات أكثر فاعلية, وظهر ما يسمى بالتعلم المدمج (سلامة, 2006)، كادئ كتطور طبيعي للتعلم الالكتروني وهذا النوع من التعلم كما يذكر سلامة (2006) لا يلغي التعلم الالكتروني ولا التعلم التقليدي بل هو مزيج من الاثنين معاً, لا نلغي التطور التكنولوجي ولكن نستخدمه بشكل وظيفي في فصولنا العادية أو في المعامل

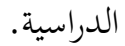

ومن هنا تبلور مفهوم التعلم المدمج كإستراتيجية حديثة في التدريس و كتطور طبيعي للتعلم الالكتروني كونه يجمع بين التعلم الالكتروني و من خلال استخدام التقنية الحميثة في التدريس التعليم التقليدي. ويشير واقع الممارسة التعليمية التعلمية إلى إن هناك ثمة حاجة إلى تفعيل هذا النمط من التعلم وقد بدأ بالفعل يحل تدريجياً محل

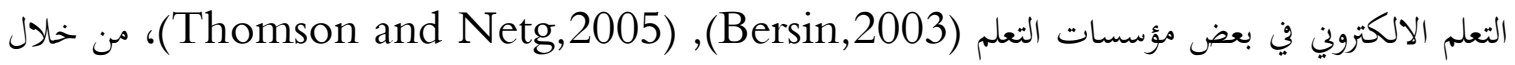
استخدام التقنية الحديثة في التدريس دون التخلي عن الواقع التعليمي المعتاد و الحضور إلى غرفة الصف ومن ثم التركيز على التفاعل المباشر داخل غرفة الصف عن طريق استخدام آليات الاتصال الحديثة كالحاسوب وشيكات الاتصال و بوابات الانترنت, وعليه يمكن وصف هذا التعلم بأنه الكيفية التي تنظم بها المعلومات و المواقف والخبرات التربوية التي تقدم للمتعلم عن طريق الوسائط المتعددة التي توفرها التقنية الحديثة. وجاءت هذه الدراسة في محاولة تقصي فاعلية استخدام التعلم المدمج في تنمية تحصيل الطلبة في مادة الرياضيات. البند الاول 


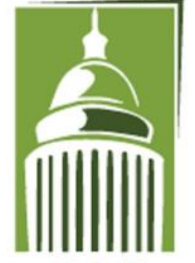

AR F
Global Proceedings Repository

American Research Foundation

ISSN 2476-017X

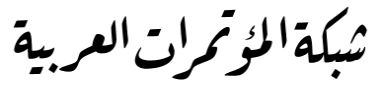

http://arab.kmshare.net/

Available online at http://proceedings.sriweb.org

لاحظت الباحثة من خلال عملها في ميدان التدريس في المدارس الحكومية بفلسطين, تدنياً في مستوى تحصيل الطلاب في مادة الرياضيات من خلال الأنشطة الصفية والاختبارات الشهرية والفصلية, حيث يتم التمييز بين أداء الطلاب بالاعتماد على عمليات الحفظ والتلقين وهي الطريقة المعتمدة, ونتج عن ذلك قصور في مهارات التفكير العلمي, واكتساب المفاهيم العلمية لديهم، وتدني في تحصيل الطلاب, في غالبية المقررات الدراسية وخاصة الرياضات, حيث يعاني طلبة الصف السابع من صعوبات في تعلم الرياضات, ويعزى ذلك لاستخدام الطرق التقليدية في التعليم والتي تؤدي إلى تكوين تفسيرات علمية خاطئة وغير مقبولة علميًا لدى الطلبة نتيجة لعدم تطبيق المنهج السليم في التفكير.

تبين للباحثة مما سبق أنه يوجد ضعف في تحصيل طلبة المرحلة الأساسية, وتحاول الباحثة مواجهة هذه المشكلة بإعداد برنامج

قائم على التعلم المدمج, ودراسة فاعليته في تنمية التحصيل, وذلك من خلال الإجابة عن السؤال الرئيس للبحث وينص على: "ما فاعلية برنامج مقترح في الرياضيات قائم على التعلم المدمج في تنمية التحصيل لدى طلبة المرحلة الأساسية في فلسطين؟

$$
\text { ويتفرع من هذا السؤال الرئيس الأسئلة الفرعية الآتية: }
$$

1. ما أسس بناء البرنامج المقترح في الرياضيات القائم على التعلم المدمج في تنمية التحصيل في الرياضيات لدى طلبة

$$
\text { الصف السابع الأساسي؟ }
$$

2. ما التصور المقترح لبرنامج في الرياضيات قائم على التعلم المدمج في تنمية التحصيل في الرياضيات لدى طلبة الصف

$$
\text { السابع الأساسي؟ }
$$

$$
\text { 3. ما فاعلية البرنامج المقترح في تنمية التحصيل في الرياضيات لدى طلبة الصف السابع الأساسي؟ }
$$

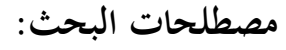

التعلم المدمج: عرفه سيفين (2011): هو أسلوب تدريسي يزاوج بين توظيف تكنولوجيا الحاسوب والانترنت على وجه الخصوص, والأساليب الاعتيادية التي ألفها المدرسون, ففي هذا النوع من التعلم يتمكن المتعلم من إعادة ما شرح له في اللقاء

$$
\text { الصفي والتأمل في تعلمه الذاتي بما يتناسب مع قدراته. }
$$

التعريف الإجرائي للباحثة للتعلم المدمج: طريقة من طرائق التعليم والتعلم يدمج فيه التعلم الالكتروي والتعليم التقليدي, بإعداد برنامج يعتمد على التقنيات الحلديثة, باستخدام تقنيات الاتصال الحديثة كالحاسوب وشبكات المعلومات وبوابات الانترنت بما يتناسب خصائص الطلبة, واحتياجاهم وطبيعة مادة الرياضيات, بهدف تنمية التحصيل لطلبة الصف السابع الأساسي في 


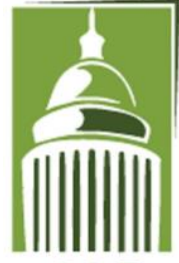

AR F
Global Proceedings Repository

American Research Foundation

ISSN 2476-017X

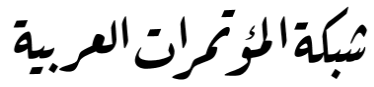

http://arab.kmshare.net/

Available online at http://proceedings.sriweb.org

التحصيل: يعرفه (اللقاني و الجمل، 2003): أنه مدى استيعاب التلاميذ لما تعلموه من خبرات معينه من خلال مقررات دراسية ويقاس بالاختبار التحصيلي المعد لهذ الغرض.

والتعريف الإجرائي للباحثة: الإنجاز المعريف هو مقدار ما تحصله التلميذات من المعرفة العلمية بعد دراستهن لوحدة الكهرباء في

حياتنا من مقرر منهاج العلوم للصف السادس الابتدائي، ويقاس بالدرجة التي تحصل عليها في الاختبار التحصيلي المعد

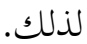

أهداف البحث:

1. تصميم برنامجاً مقترحاً قائماً على التعلم المدمج لتدريس وحدات الفصل الدراسي الثاني من مقرر الرياضيات للصف السابع الأساسي في المدارس الحكومية التابعة لمديرية تربية وتعليم الخليل في فلسطين.

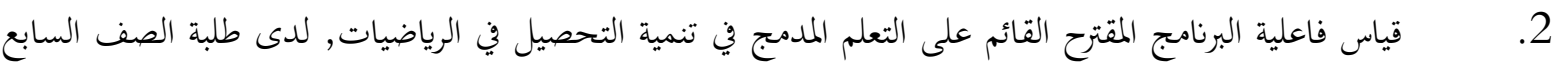
الأساسي في المدارس الحكومية التابعة لمديرية تربية وتعليم الخليل في فلسطين.

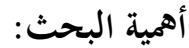
قد يفيد البحث الحالي كل من:

- مخططي المناهج: تقديم برنامج مقترح قائم على التعلم المدمج, قد يساعد مخططي المناهج في تخطيط وحدات دراسية من مناهج الرياضيات وفقا للتعلم المدمج.

- معلمي الرياضيات: تقديم أدلة لمعلمي الرياضيات للتدريس باستخدام البرنامج المقترح القائم على التعلم المدمج وتقديم اختبار للتحصيل في الرياضيات , للاستفادة منها، وتصميم أدوات مماثلة لوحدات أخرى لصفوف تعليمية أخرى.

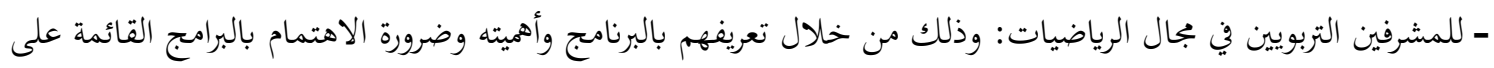
التعلم المدمج، وذلك أثناء ممارستهم لمهامهم الإشرافية. - للطلبة: تقدم للطلبة برنامج قائم على التعلم المدمج يساعد الطلبة على تنمية التحصيل في الرياضيات.

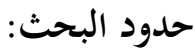




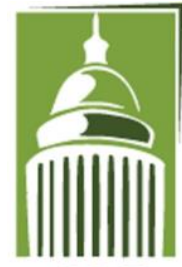

AR F
Global Proceedings Repository

American Research Foundation

ISSN 2476-017X

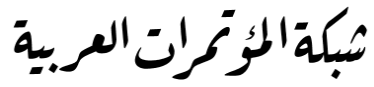

http://arab.kmshare.net/

Available online at http://proceedings.sriweb.org

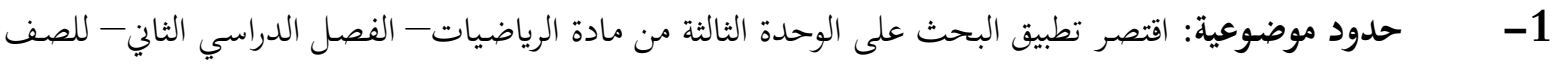
السابع الأساسي للمنهاج الفلسطيني.

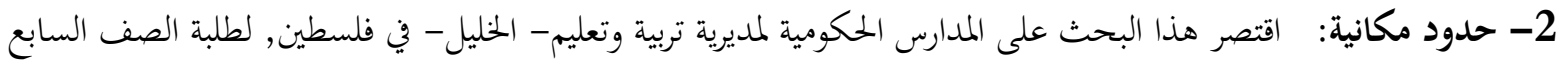
الأساسي, مدرسة اسحق القواسمة الأساسية. 3- حدود زمانية: استغرق تطبيق هذا البحث 4 أسابيع خلال الفصل الدراسي الثاني من العام 2019/2018م.

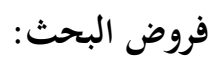
سعت الباحثة خلال البحث الحالي التحقق من الفرضيتين التاليتين: 1- يوجد فرق دال إحصائيا عند مستوى (0.05) بين متوسطي درجات طالبات المجموعة التجريية والمجموعة الضابطة, في التطبيق البعدي لإختبار التحصيل لصالح طالبات المجموعة التجريية.

2- يوجد فرق دال إحصائيا عند مستوى (0.05) بين متوسطي درجات طالبات المجموعة التجريبية, في التطبيقين القبلي والبعدي لإختبار التحصيل لصالح التطبيق البعدي. البند الثاني الإطار النظري والدراسات السابقة

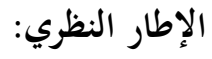

\section{Blended Learning التعلم المدمج}

بالرغم من ميزات الطريقة التقليدية من توفير الوقت والجههد للمعلم ،ومن إثراء خبرات المتعلمين بخبرات وبحارب المعلم الإبداعية

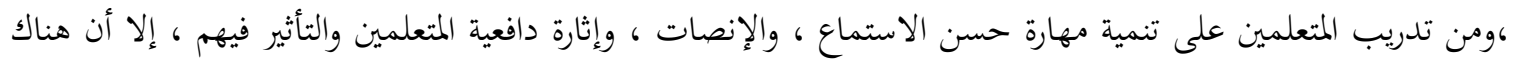

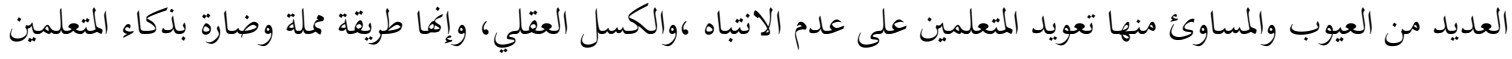

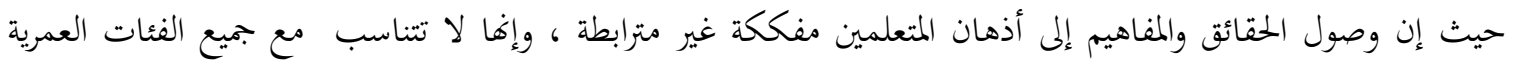

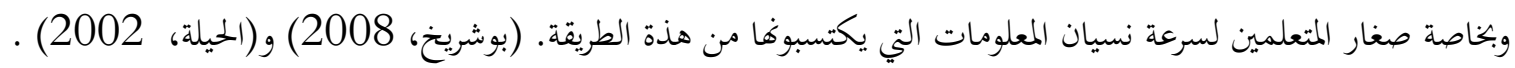




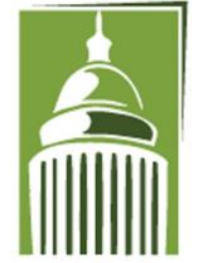

AR F
Global Proceedings Repository

American Research Foundation

ISSN 2476-017X

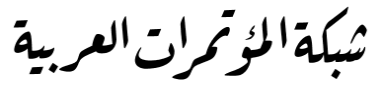

http://arab.kmshare.net/

Available online at http://proceedings.sriweb.org

لذلك ، كان لابد من ادخال منظومة تعليمية تقدم البرامج التعليمية أو التدريبية للمتعلمين في أي وقت وفي أي مكان باستخدام تقنيات المعلوماتية والاتصالات التفاعلية لتوفير بيئة تعليمية متعددة المصادر بطريقة متزامنة او غير متزامنة دون الالتزام بمكان محدد. ( سالم، 2004).

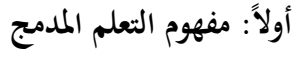

تعددت التعريفات حول العلم المدمج وذلك نظراً لطبيعة الاهتمام والتخصص حيث انه مفهوم قديم حديث. فهناك عدة مسميات له منها التعلم المزيج "Blended Learning" ، التعلم الخليط , والتعلم المدمج والتعلم التمازجي ،

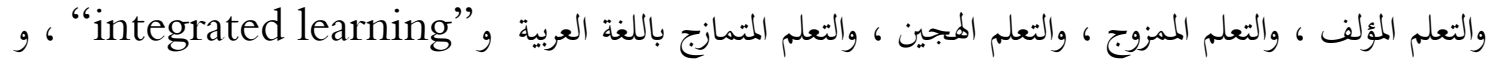

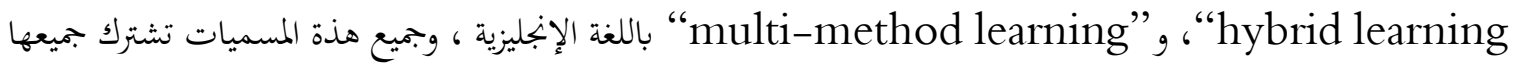
في أها تنظر للتعلم الناتج انه مزج بين أدوات التعلم الالكتروني وطرقه مع ادوات التعلم التقليدي وطرقه ، وفقا لمتطلبات الموقف التعليمي (عبد العاطي والمخيني، 2010 ). وقد تعددت تعريفات التعلم المدمج وتدور حول معنى واحد وهدف واحد ومن هذه التعريفات: يعرف عطية(2003) التعلم المددج بأنه "احد صيغ التعلم أو التعليم الذي يدمج فيها التعلم الالكتروني مع التعليم التقليدي في إطار واحد, حيث توظف أدوات التعلم الالكتروي سواء المعتمدة على الكمبيوتر أو المعتمدة على الشبكات في الدروس والمحاضرات, وفي جلسات التدريب التي تتم غالبا في قاعات الدرس الحقيقية المجهزة بإمكانية الاتصال بالشبكات". اتفق كل من ربيع رمود (2011) وشوملي قسطندي( 2007) وحسن زيتون(2005) أن التعلم المدمج استخدام المستحدثات التكنولوجية في التعلم دون التخلي عن الواقع التعليمي التقليدي والحضور في حجرة الدراسة, ويتم التركيز على التفاعل المباشر داخل غرفة الصف عن طريق استخدام آليات الاتصال الحديثة, كالكمبيوتر والشبكات وبوابات الانترنت.

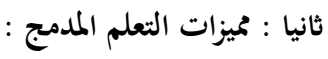
إن التعلم المدمج هو تطور منطقي وطبيعي في أجندة تطوير التعليم، وذكر كل من و المعايطة(2006) و الغامدي(2011)

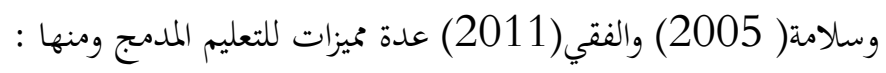
العمل على تحسين أداء المتعلم وتعلمه، رفع جودة العملية التعليمية واثراء المعرفة الانسانية، تحفيض نفقة وكلفة التعلم بالمقارنة مع التعلم الالكتروني وحدة، التواصل الحضاري والاجتماعي والإنساني في مختلف الثقافات، الوصول الى أكبر عدد من المتعلمين في أقصر وقت، التعليم فيه يكون بطريقة تفاعلية، يركز على الجوانب المعرفية والوجدانية والمهارية، جعل دور 


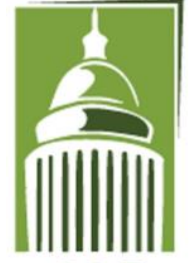

AR F
Global Proceedings Repository

American Research Foundation

ISSN 2476-017X

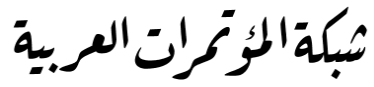

http://arab.kmshare.net/

Available online at http://proceedings.sriweb.org

المعلمين قادرة ومرشدين للمتعلمين، اعداد جيل على تواصل دائم بالمعرفة وومواكبة تقنيات ومتطلبات العصر، توفير التناغم تحسين البحاهات المتعلمين نحو التعلم والتعليم ونخو المؤسسة التعليمية، والانسجام بين متطلبات التعلم وبرنامج التعلم، الانتقال من التعلم الجماعي الى التعلم المتمركز حول الطالب، يتيح الفرصة للاهل التواصل مع ابنائهم وتقديم المساعدة لهم. بالإضافة أن هناك موضوعات يصعب تدريسها الكترونيا بالكامل وبالتالي فإن التعلم المدمج يكون الحل لحل مشكلة كهذه

ثالثًا: نماذج التعلم المدمج ومن النماذج التي بنيت أساسا للتعلم المدمج: 1. نموذج ( ODP, 2003, htt: //www. ojp. gov/blendedlearning ) للتصميم التعليمي لبرامج التعلم المددج, ويتكون من خمسة مراحل : أ-مرحلة التحليل : مرحلة مهمة في تطبيق أسلوب الدمج في التعلم, يتم فيها تحديد من هم المتعلمين, وما الذي يعرفونه, وما

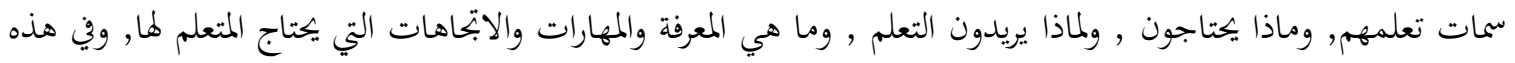
المرحلة يتم تقييم الاحتياجات, وتحليل المهام التعليمية, وتحديد الأهداف التعليمية , وتحديد طرق التقديم, وتلخيص الإطار العام للمقرر - (- n

ب-مرحلة التصميم: مرحلة يتم فيها التخطيط لإستراتيجية تطبيق برنامج التعلم المدمج من خلال تحديد عناصر التعلم وهي

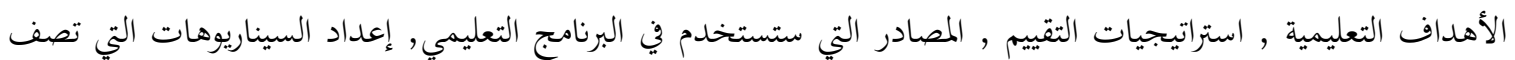
طريقة تقديم المحتوى,تحديد النشطة العملية وطرق تقديم التغذية الراجعة. ج-مرحلة التطوير: يتم فيها إنتاج المواد التعليمية الميسرة لعملية التعلم, وكل الوسائل التي تدعم العملية التعليمية.وتعتمد هذهـ المرحلة على مرحلتي التحليل والتصميم. د-مرحلة التنفيذ: تمدف هذه المرحلة إلى تطبيق برنامج التعلم المدمج في ضوء الخطوات التي تم تحديدها مسبقا خلال مرحلة التصميم وطرق تقديم التعلم وانجاز المهمة التعليمية في الوقت المحدد.

هـ-مرحلة التقويم: مرحلة قياس مدى تحقق الأهداف, ونجاح البرنامج التعليمي باستخدام الأدوات التقويم التي تم بناؤها.

2. نموذج هانج لتصميم التعلم المدمج (Haung,2005 ). حددت ثلاثة مراحل رئيسية لهذا التصميم وهي: 


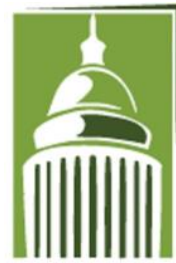

AR F
Global Proceedings Repository

American Research Foundation

ISSN 2476-017X

Available online at http://proceedings.sriweb.org

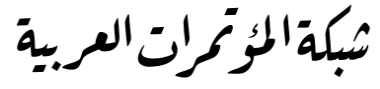

http://arab.kmshare.net/

1 التحليل القبلي: Pre-analysis

للتحقق من إمكانية تطبيق التعلم المدمج وتضم ثلاثة عوامل رئيسية وهي:

- - التقييم المنتظم لمعرفة التعلم السابق وأنماط واستراتيجيات التعلم.

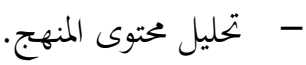

- - تحليل مواصفات بيئة التعلم ويجب تحديد الأنشطة التعليمية وطرق التعلم بوضوح وهذا يساعد في كتابة تقرير التحليل الأولي.

Design of Activates and Resources تصميم الأنشطة والمصادر

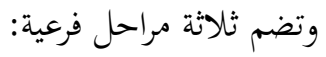

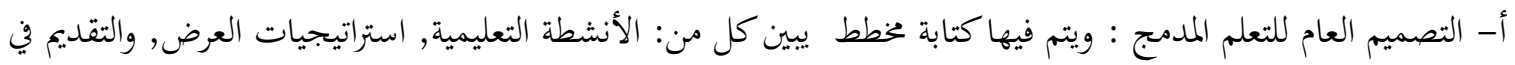
بيئة التعلم المدمج, الدعم التعليمي, وكيف تقدم لكمادم التغذية الراجعة للتلميذ أثناء التعلم. ب- تصميم وتطوير المصادر وتشتمل على: اختبار المتوى, تطوير المصادر وإنتاجها, تقديم المصادر للطالب . لمالت

ج- تصميم الأنشطة وتحتوي على :تعريف وتحديد الأداء المطلوب, الأهداف المتعلقة بالأنشطة التعليمية, تنظيم الأنشطة التعليمية, طريقة تقويم الأنشطة التعليمية.

$$
\text { 3- التقييم التعليمي }
$$

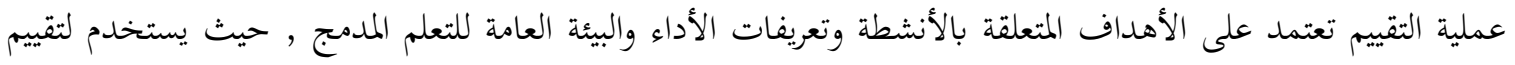

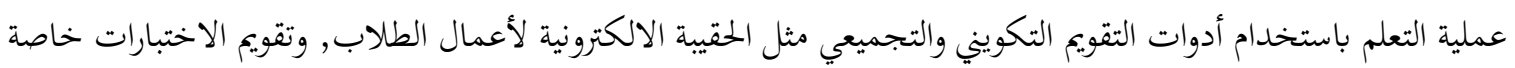
التي تبث عبر الشبكة وايضا يتم تنظيم الأنشطة التعليمية وتقويمها.

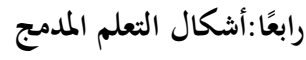

ويمكن توظيف التعلم المدمج في عمليتي التعليم والتعلم في ثلاثة أشكال كما صنفها زيتون(2005) كالتالي:

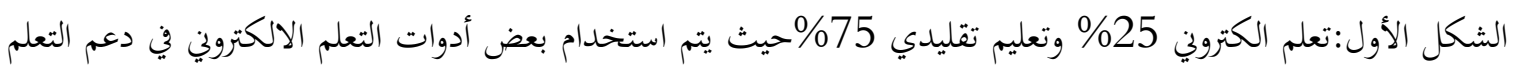
الصفي (التقليدي) 


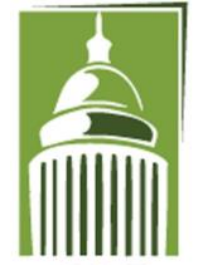

AR F
Global Proceedings Repository

American Research Foundation

ISSN 2476-017X
شبكة المؤومرات العر.بة

http://arab.kmshare.net/

Available online at http://proceedings.sriweb.org

الشكل الثاني:تعلم الكتروفي 50\% وتعلم تقليدي 50\% ويتضمن الجمع بين التعلم الصفي والتعلم الالكتروني داخل غرفة

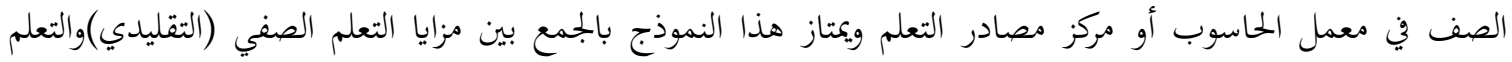
الالكتروني المتعلم هو الأساس في عملية تعلمه.

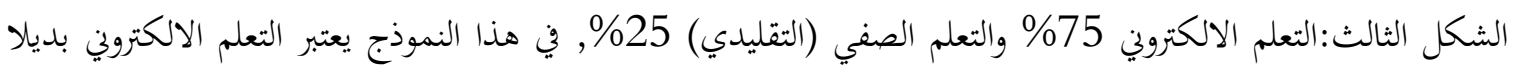
للتعلم الصفي ويسميه البعض التعلم الافتراضي.

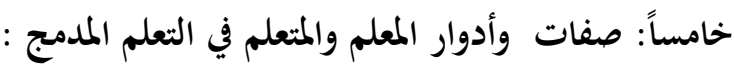
يعد المعلم المتطلب الأول من المتطلبات البشرية في منظومة التعلم المدمج فهو الموجه والمرشد والميسر والمدير للعملية التعليمية والمصمم للأنشطة والمبسط للمحتوى ولدية القدرة على الجمع بين التدريس التقليدي والالكتروني هذا ما ذكرته

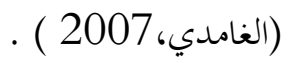

وقد ذكرت كوجك وآخرون (2008) أن على المعلم توضيح طريقة التدريس بالتعلم المدمج للمتعلمين ولأولياء الأمور ليشاركو

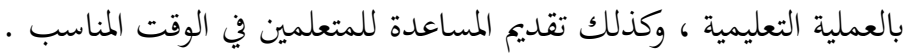

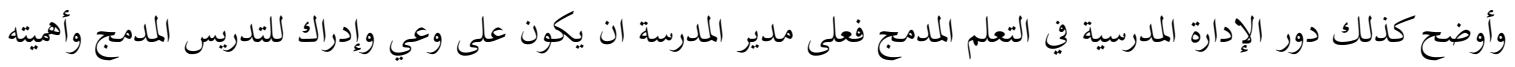
وأهدافه في حين ذكر برهوم(2013) بعض الصفات والأدوار التي على المتعلم الاتصاف بها ومنها أن يكون عنصر فاعل ومتفاعل

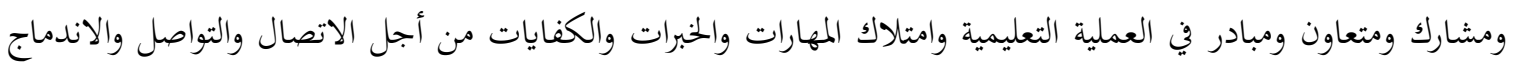

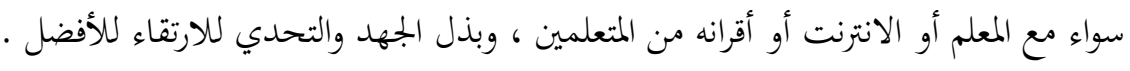

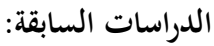

دراسة صبري (2017) هدفت الدراسة إلى التعرف على فاعلية برنامج قائم على التعلم المدمج في تنمية تحصيل تلاميذ الصف السادس الابتدائي في الرياضيات ودافعيتهم نخوه في وحدتي الهندسة والقياس والاتحاه نحو التعليم المدمتج، ولتحقيق

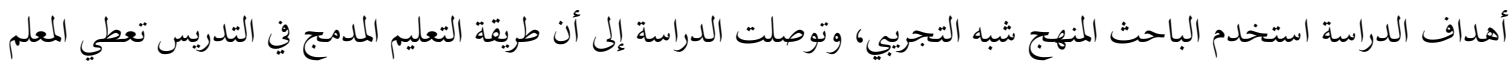

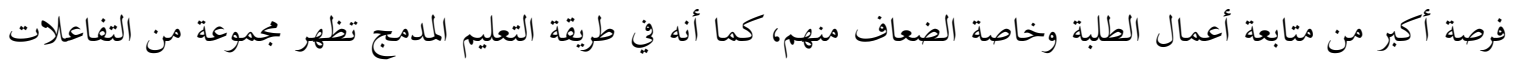

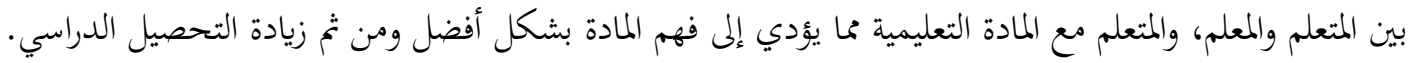
دراسة علي(2012) هدفت الدراسة إلى قياس فاعلية برنامج قائم على التعلم المدمج في تنمية التحصيل والتفكير الابتكاري

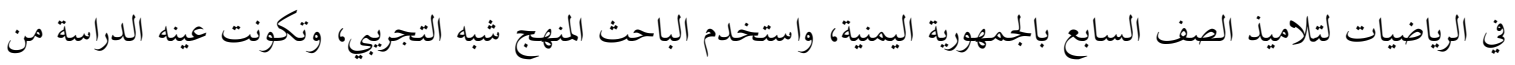




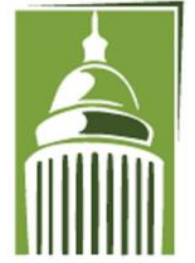

AR F
Global Proceedings Repository

American Research Foundation

ISSN 2476-017X

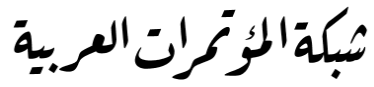

http://arab.kmshare.net/

Available online at http://proceedings.sriweb.org

65 تلميذا من الصف السابع ، وتم التوصل للنتائج التالية: يوجد فرق دال إحصائياً اختبار للتفكير الابتكاري، بين متوسطات

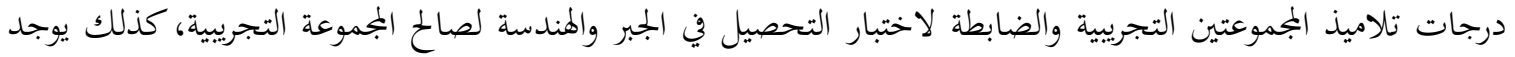

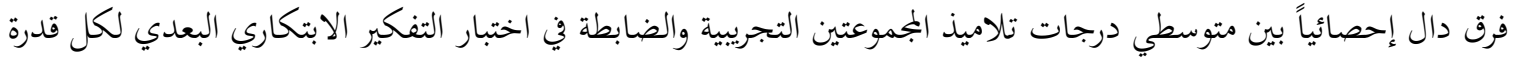
فرعية من قدرات التفكير الابتكاري لصالح المجموعة التجريبية.

دراسة الجحلدي(2011) هدفت الدراسة إلى معرفة أثر استخدام التعليم المدمج على تحصيل طالبة الصف الأول المتوسط في

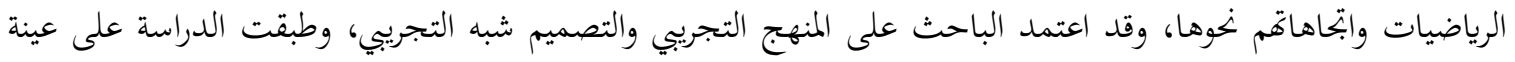

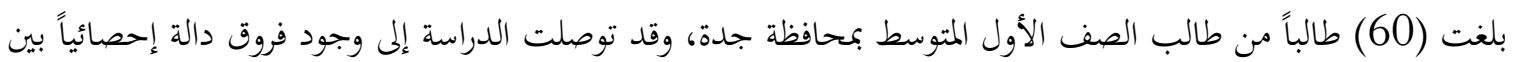

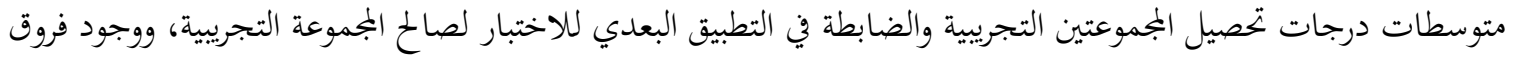
بين متوسطات درجات الجمموعتين التجريبية والضابطة في التطبيق البعدي لمقياس الاتحاه لصالح البمموعة التجريبية. دراسة الحويطي(2011)

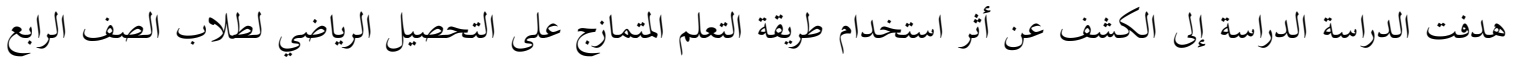

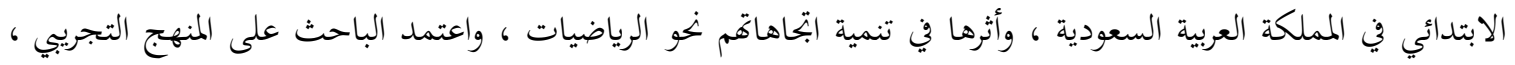

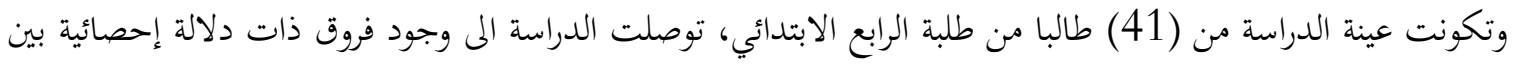

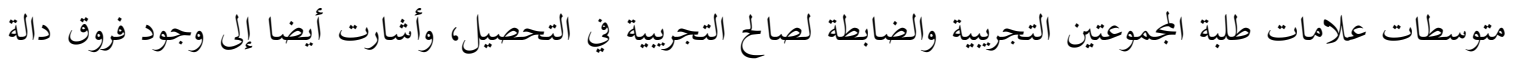
إحصائيا بين المجموعتين في ابتاهات الطلبة نحو الرياضيات ولصالح البجموعة التجريبية .

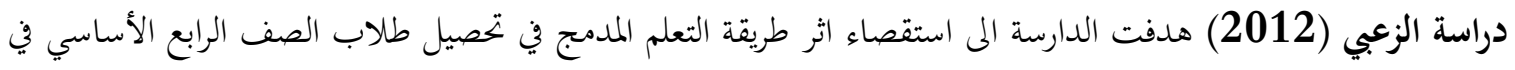

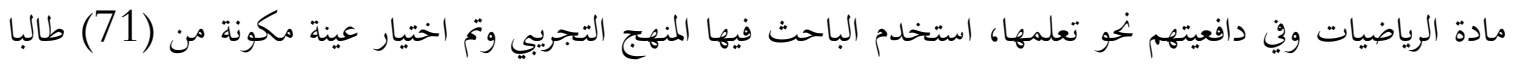

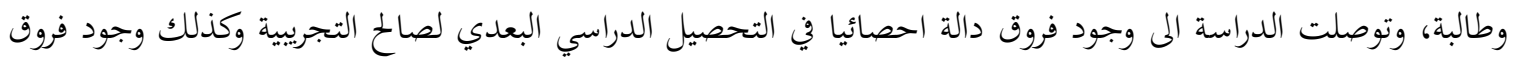
دالة احصائيا بين متوسط علامات الجموعة التجريبية على مقياس الدافعية لصالح التجريبية.

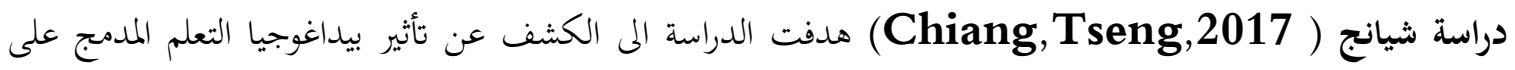

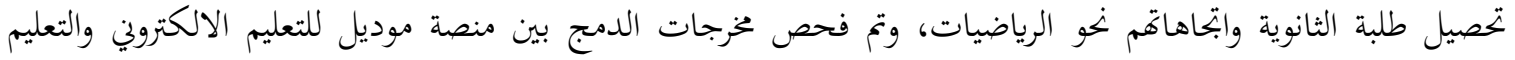

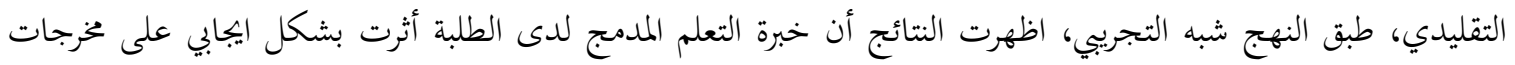
التعلم وكذلك توجهاقم نخو تعلم الرياضيات. 


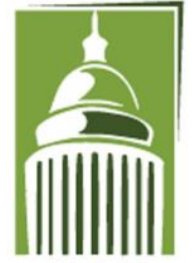

AR F

\section{Global Proceedings Repository}

American Research Foundation

ISSN 2476-017X

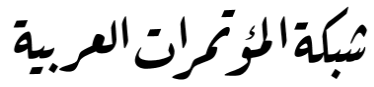

http://arab.kmshare.net/

Available online at http://proceedings.sriweb.org

دراسة بالنتين وفيرجه ( Balentyne\& Varga,2016) هدفت الدراسة الى قياس فاعلية التعلم المدمج في

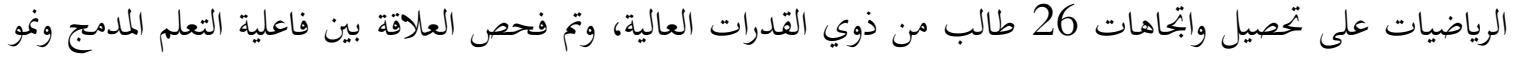

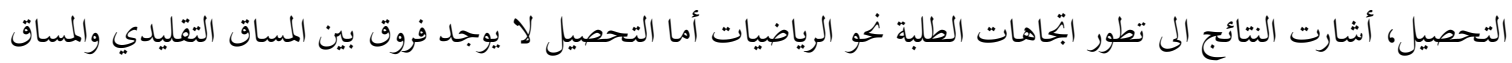

دراسة ايريلمز (Eryilmaz,2015) هدفت الدراسة الى قياس بيئة التعلم المدمج، حيث طبقت الدراسة على 110

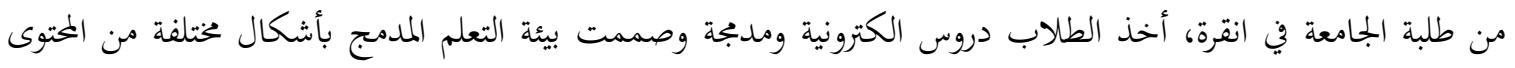

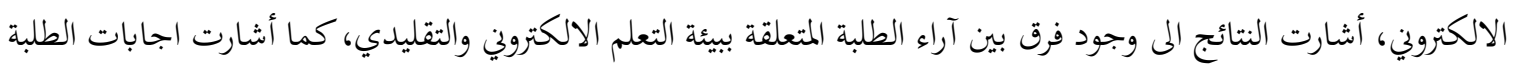

$$
\begin{aligned}
& \text { الى أفم تعلموا بشكل أفضل بإستخدام التعلم المدمج. } \\
& \text { التعقيب على الدراسات السابقة: }
\end{aligned}
$$

بعد استعراض الدراسات السابقة التي تناولت موضوع التعلم المدمج تبين للباحثة أن هناك القليل من الدراسات التي بحثت

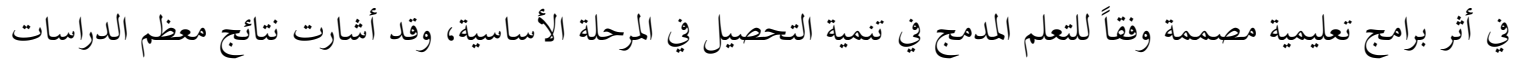

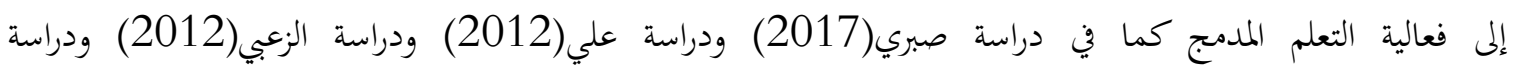

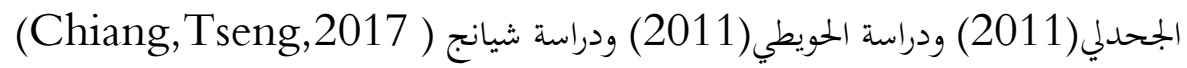

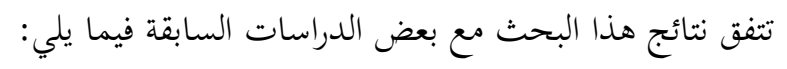

1- تفوق طلبة المجموعة التجريبية الذين درسوا باستخدام التعلم المدمج على نظائرهم طلبة المجموعة الضابطة، كما في فئل

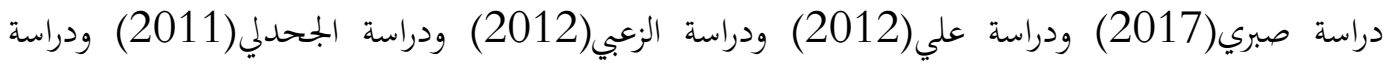

$$
\text { الحويطي(2011). }
$$

استختدام التعلم المدمج أثر بشـكل اييابي على مخرجات التعلم كما في دراسـة شــانج ( Chiang, Tseng,2017) ودراسة ايريلمز (Eryilmaz,2015) البند الثالث

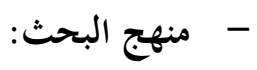

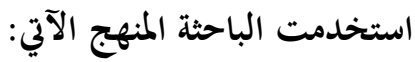

المنهج الوصفي:لإعداد الإطار النظري, والبرنامج المقترج القائم على التعلم المدمج, وأداة البحث, والمواد التعليمية. 


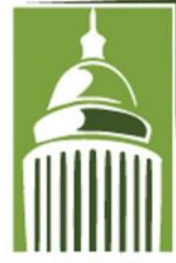

AR F
Global Proceedings Repository

American Research Foundation

ISSN 2476-017X

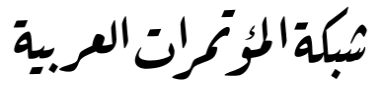

http://arab.kmshare.net/

Available online at http://proceedings.sriweb.org

المنهج شبه التجريبي: لدراسة فاعلية استخدام البرنامج المقترح القائم على التعلم المدمج, في تنمية التحصيل.

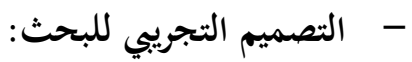

استخدمت الباحثة التصميم التجريبي للبحث في بموعتين المجموعة التجريبية (20) طالبة, طبق عليها البرنامج المقترح القائم

على التعلم المدمج, والمجموعة الضابطة (20) طالبة, تم تدريسها بالطريقة المعتادة (التقليدية), وطبقت الباحثة أداة البحث قبليًا، تم طبقت الوحدة الدراسية من خلال البرنامج المقترح القائم على التعلم المدمج, للمجموعة التجريبية, أما المجموعة الضابطة درست نفس الوحدة بالطريقة العادية, وبعد انتهاء الوحدة طبقت الباحثة أداة البحث بعديًا.

- مجتمع البحث: يتكون من جميع طلبة الصف السابع الأساسي في المدارس الحكومية التابعة لمديرية تربية وتعليم الخليل كام 2019/2018م.

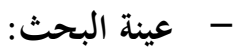

اختارت الباحثة عينة البحث بطريقة قصديه، وتمثلت عينة البحث من (40) طالبة من طالبات مدرسة اسحق القوا سمة بمديرية تربية وتعليم الخليل على النحو التالي: الصف السابع (أ)) : عدد الطالبات (20) كمجموعة بتريبية تتعلم وفق البرنامج القائم على التعلم المدمج. الصف السابع (ب): عدد الطالبات (20) طالبة كمجموعة ضابطة تتعلم بالطريقة المعتادة. اختبار التحصيل: قامت الباحثة ببناء اختبار التحصيل بالخطوات التالية: 1- تحديد الهدف من الإختبار: هدف اختبار التحصيل الم قياس تحصيل طلبة الصف السابع الأساسي باستخدام التعلم المدمج, بعد دراستهم للوحدة الدراسية المختارة. 2- تحديد نوع الإختبار: تم إعداد الإختبار من نوع الاختيار من متعدد لما يتميز ههذا النوع من الاختبارات من موضوعية التصحيح، كما أنه يقيس العديد من مخرجات ونواتج التعلم. 4- صياغة مفردات المقياس: قامت الباحثة بإعداد(30) سؤالا لكل سؤال أربع بدائل للإجابة للتقليل من أثر التخمين. 5- تصحيح أسئلة المقياس: تم تصحيح أسئلة الاختيار من متعدد بإعطاء درجة واحدة لاختيار البديل الصحيح, وصفر لكل

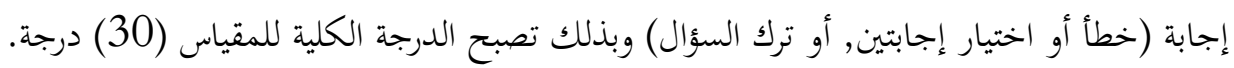




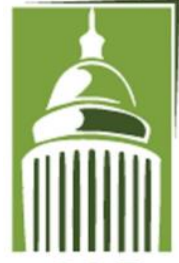

AR F
Global Proceedings Repository

American Research Foundation

ISSN 2476-017X

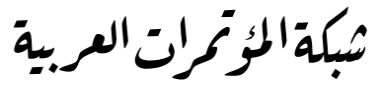

http://arab.kmshare.net/

Available online at http://proceedings.sriweb.org

6- صدق الإختبار: تم عرض الإختبار على مجموعة من السادة المحكمين والخبراء في المناهج وطرق التدريس بمدف التأكد من:

$$
\text { - }
$$

تم تطبيق الإختبار على بجموعة استطلاعية من طالبات الصف السابع الأساسي بمدرسة اسحق القوا سمة الأساسية للبنات

$$
\text { وذلك بمدف تحديد: }
$$

أ- زمن المقياس: تم حساب زمن الإجابة عن أسئلة الإختبار بإيجاد متوسط الزمن الذي استغرقته أول طالبة أهت الإجابة عن

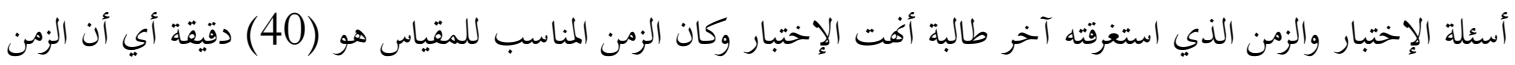

$$
\text { المناسب لتطبيق الإختبار هو حصة دراسية واحدة. }
$$

ب-ثبات الإختبار: تم تطبيق الإختبار على المجموعة الاستطلاعية وتم التطبيق مرة أخرى بفاصل زمني بلغ أسبوعين وتحديد معامل

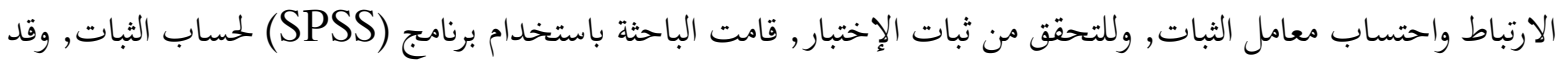

$$
\text { تم حساب معامل الثبات بطريقتين هما: }
$$

- - طريقة معامل كرونباخ ألفا "Cronbach Alpha":تم حساب الاتساق الداخلي بين فقرات اختبار التحصيل,

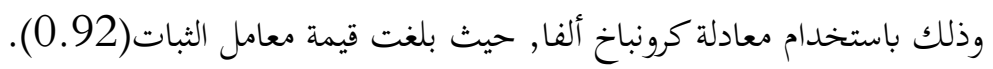

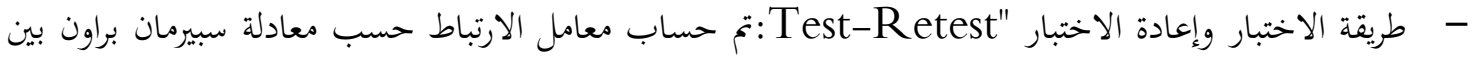
التطبيقين, وبلغت قيمة معامل سبيرمان براون لإختبار التحصيل(0.97).

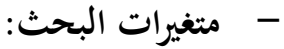

المتغير المستقل: البرنامج المقترح القائم على التعلم المدمج.

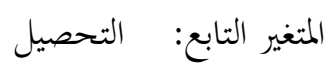

البند الاخير 
Global Proceedings Repository

American Research Foundation

ISSN 2476-017X

Available online at http://proceedings.sriweb.org

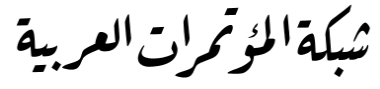

http://arab.kmshare.net/

\section{نتائج البحث وتفسيرها}

يتناول هذا الفصل عرضاً لنتائج البحث التي توصلت إليها الباحثة وفيما يأتي عرض للنتائج في هذا الفصل تبعاً للمتغيرات التابعة كما يلي:

أولاًَ- النتائج المتعلقة بفاعلية البرنامج القائم على التعلم المدمج في تنمية التحصيل في الرياضيات لدى طلبة الصف السابع

$$
\text { الأساسي: }
$$

للإججابة عن السؤال الفرعي الثالث: " ما فاعلية البرنامج القائم على التعلم المدمج في تنمية التحصيل في الرياضيات لدى طلبة الصف السابع الأساسي في فلسطين؟" واختبار صحة الفرض التجريبي الأول: "يوجد فروق ذات دلالة إحصائية بين متوسطي درجات طالبات المجموعتين الضابطة والتجريبية في اختبار التحصيل البعدي ككل, لصالخ المجموعة التجريبية التي تدرس باستخدام البرنامج.", اتبعت الباحثة الخطوات التالية:

1. للإجابة على هذا التساؤل قامت الباحثة بتطبيق اختبار التحصيل بعد الانتهاء من دراسة البرنامج مباشرة, وتم حساب المتوسطات الحسابية, ودرجات الحرية, وقيمة (ت) للعينتين المستقلتين( Independent Samples (T-Test كما هو موضح في الجدول (1).

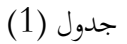

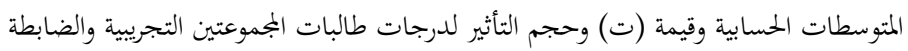
في اختبار التحصيل البعدي الكلي (الدرجة الكلية = 30). 


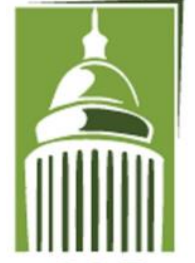

AR F
Global Proceedings Repository

American Research Foundation

ISSN 2476-017X

Available online at http://proceedings.sriweb.org

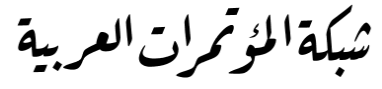

http://arab.kmshare.net/

\begin{tabular}{|c|c|c|c|c|c|}
\hline حجم التأثير & وديم (ت) & الضمابطة المة & التجموعة التجريبية & النهائية & مستويات الاختبار \\
\hline ***1.12 & $* 3.53$ & 16.70 & 23.60 & 30 & الدرجة الكلية لإختبار \\
\hline
\end{tabular}

يتضح من الجدول رقم (1) أن قيمة (ت) المحسوبة تساوي(3.53))، وهي دالة إحصائيًا عند مستوى الدلالة

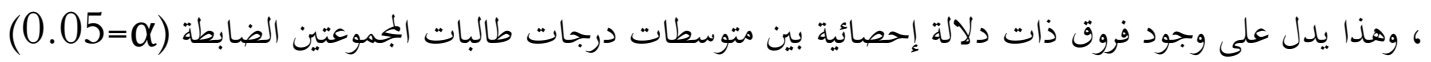

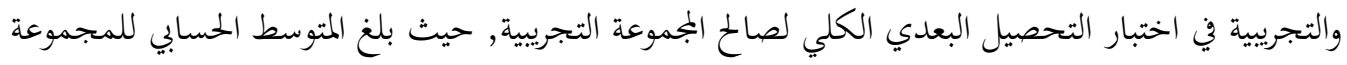

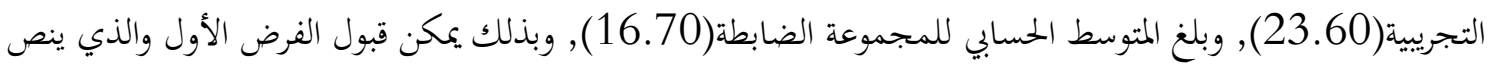

على أنه: " توجد فروق ذات دلالة إحصائية بين متوسطات درجات طالبات المجموعتين الضابطة والتجريبية في اختبار التحصيل البعدي الكلي لصالح المجموعة التجريبية التي تدرس باستخدام البرنامج", وهذا يعني أن هناك أثر للبرنامج القائم

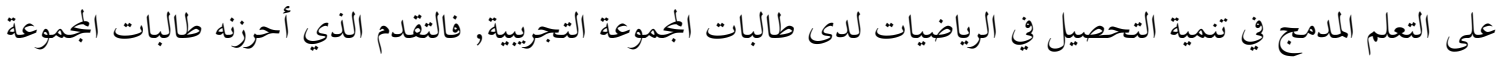

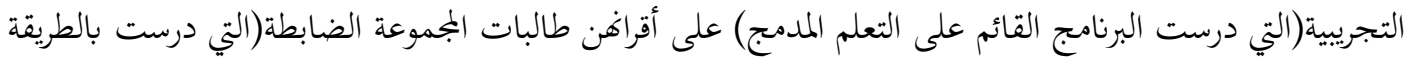

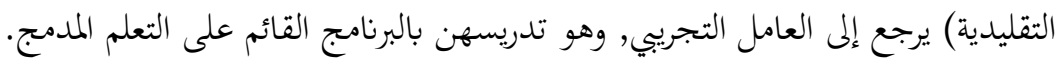

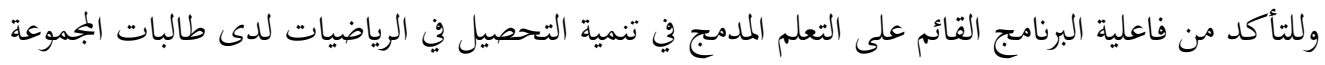
التجريبية, تم حساب حجم الأثر ( ) حسب معادلة مؤشر كوهين لحجم الأثر وذلك لتحديد تأثير المتغير المستقل (البرنامج

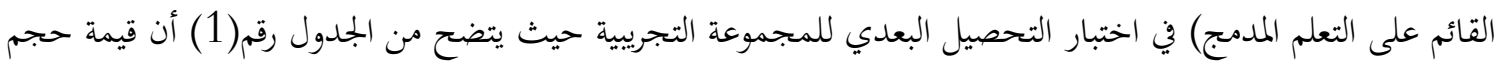

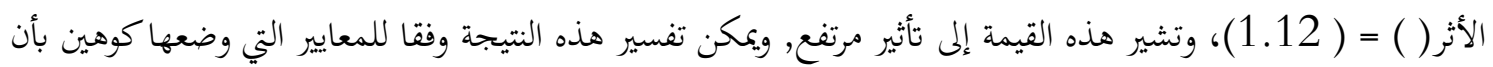

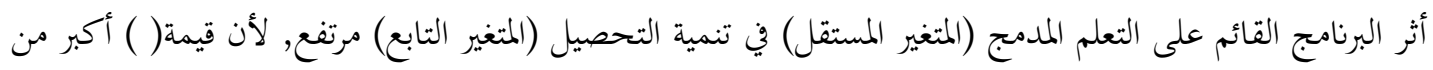
0.80 


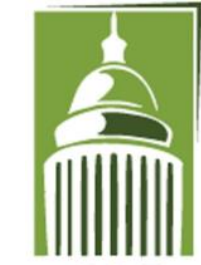

AR F

\section{Global Proceedings Repository}

American Research Foundation

ISSN 2476-017X

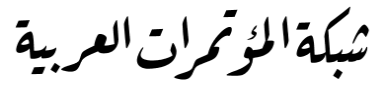

http://arab.kmshare.net/

Available online at http://proceedings.sriweb.org

2.

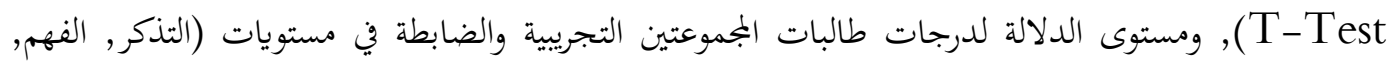

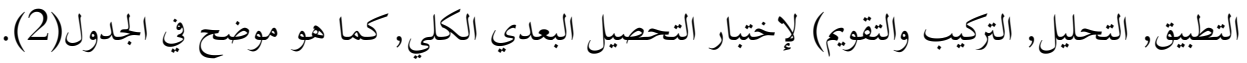

جدول (2)

المتوسطات الحسابية وقيمة (ت) وحجم التأثير لدرجات طالبات الجموعتين التجريية والضابطة

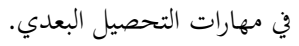

\begin{tabular}{|c|c|c|c|c|c|}
\hline حجم التأثير & قودلالتها "تا & الضابطة & التجريية & العلامة النهائية & المستويات \\
\hline 0.67 & $* 2.10$ & 4.80 & 6.25 & 8 & التذكر \\
\hline ***1.04 & $* 3.28$ & 4.20 & 5.95 & 7 & الفهم \\
\hline 0.40 & 1.25 & 3.10 & 3.50 & 5 & التطبيق \\
\hline ***1.28 & $* 4.02$ & 1.40 & 2.30 & 3 & التحليل \\
\hline ***1.49 & $* 4.70$ & 2.15 & 3.30 & 4 & التركيب \\
\hline ***1.60 & *5.06 & 1.05 & 2.30 & 3 & التقويم \\
\hline ***1.12 & $* 3.53$ & 16.70 & 23.60 & 30 & التحرجة الكلية لإختبار \\
\hline
\end{tabular}

تشير نتائج الجدول (2) أن متوسطات أداء المجموعة التجريبة التي درست باستخدام البرنامج القائم على التعلم المدمج في

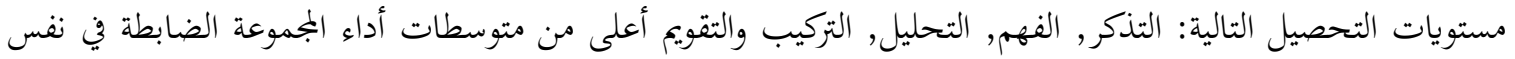

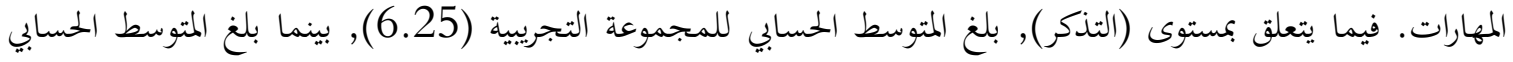

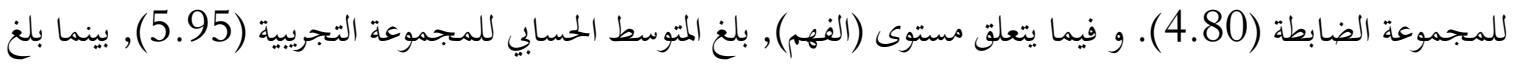

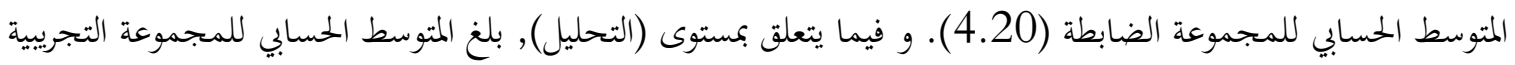
(2.30), بينما بلغ المتوسط الحسابي للمجموعة الضابطة (1.40). و فيما يتعلق مستوى (التركيب), بلغ المتوسط الحسابي 


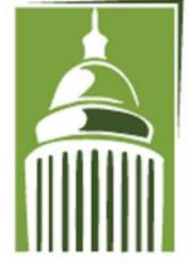

AR F

\section{Global Proceedings Repository}

American Research Foundation

ISSN 2476-017X

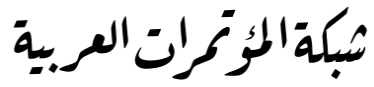

http://arab.kmshare.net/

Available online at http://proceedings.sriweb.org

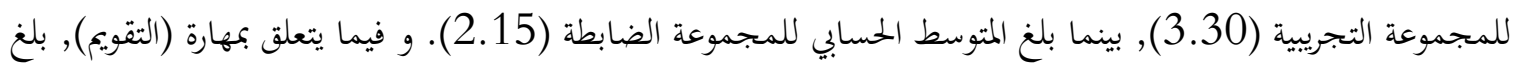
المتوسط الحسابي للمجموعة التجريية (2.30), بينما بلغ المتوسط الحسابي للمجموعة الضابطة (1.05).

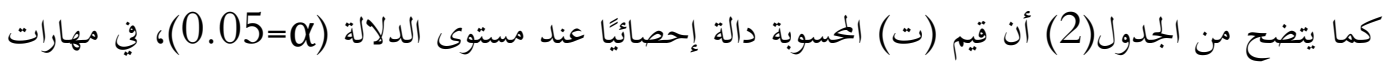

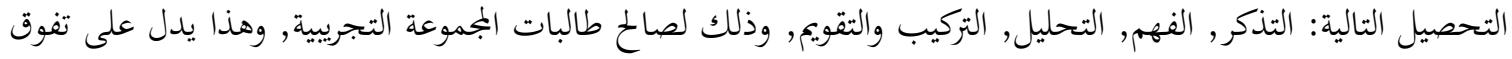

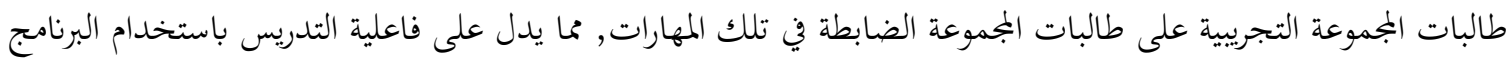

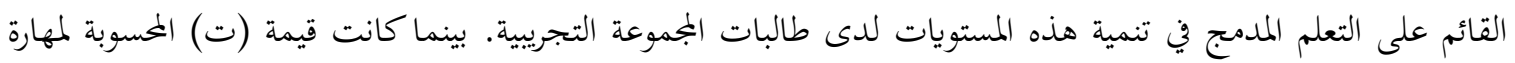

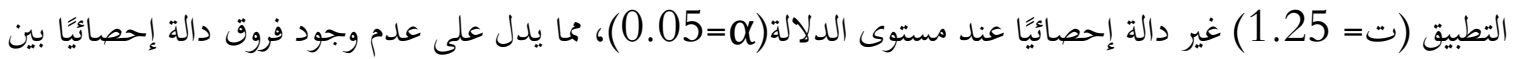

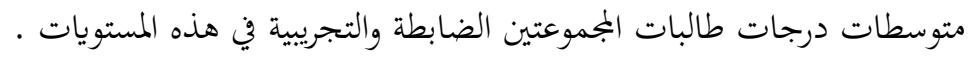

3. وللتأكد من وجود أثر للبرنامج القائم على التعلم المدمج على طالبات المجموعة التجريبية, وتحسن أدائهم في اختبار

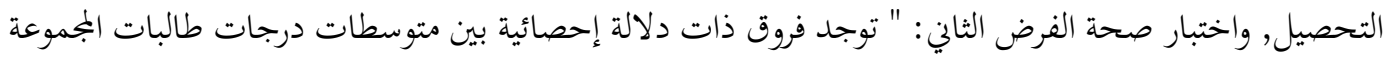

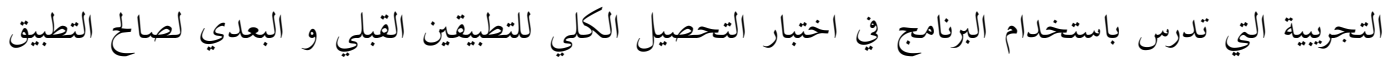

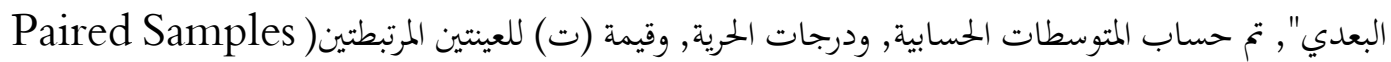
T-Test

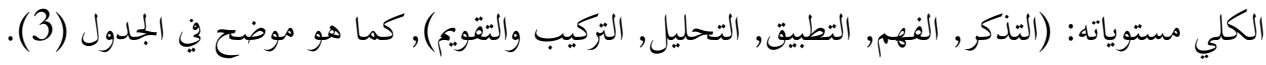

جدول (3)

المتوسطات الحسابية وقيمة (ت) ونسبة الكسب لبلاك لدرجات طالبات الجموعة التجريية للتطبيقين القبلي والبعدي في اختبار التحصيل. 


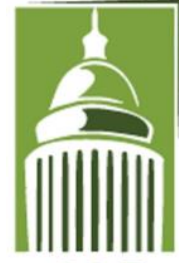

AR F
Global Proceedings Repository

American Research Foundation

ISSN 2476-017X

Available online at http://proceedings.sriweb.org

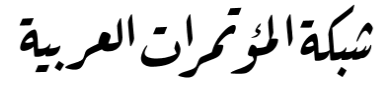

http://arab.kmshare.net/

\begin{tabular}{|c|c|c|c|c|c|}
\hline للكسبة المعدلة & قودلالتها "تا" & بعدي & قبلي & الدرجة النهائية & المستويات المعرفية \\
\hline ***0.77 & *39.00 & 6.25 & 4.30 & 8 & التذكر \\
\hline **1.29 & *26.91 & 5.95 & 2.35 & 7 & الفهم \\
\hline **1.36 & *18.43 & 3.50 & 0.15 & 5 & التطبيق \\
\hline ***1.30 & *17.62 & 2.30 & 0.55 & 3 & التحليل \\
\hline ***1.56 & *18.49 & 3.30 & 0.30 & 4 & التركيب \\
\hline ***1.49 & *11.80 & 2.30 & 0.10 & 3 & التقويم \\
\hline **1.24 & *25.35 & 23.60 & 7.75 & 30 & اختبار التحصيل الكلي \\
\hline
\end{tabular}

من خلال نتائج الجدول (3) يلاحظ ارتفاع مستوى أداء طالبات المجموعة التجريبية في التطبيق البعدي مقارنة

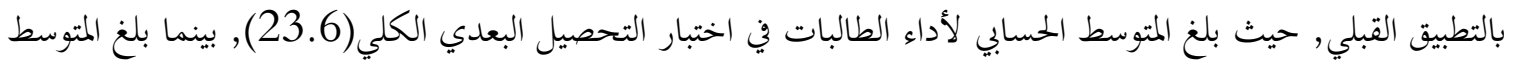

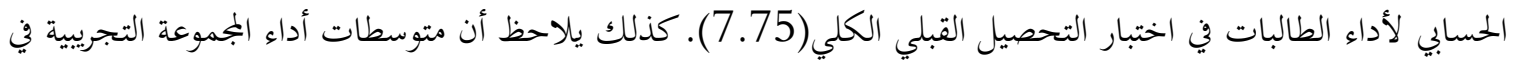

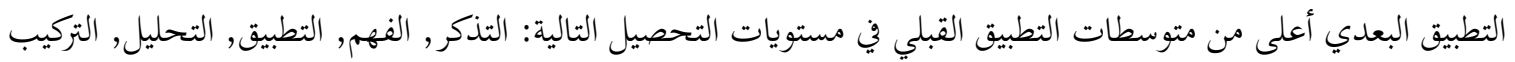

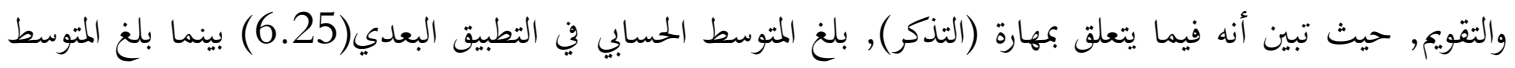

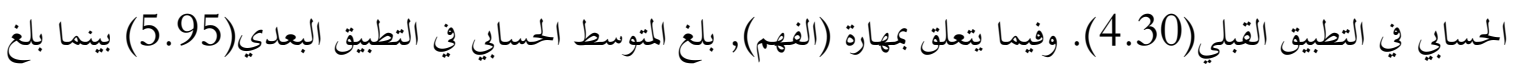

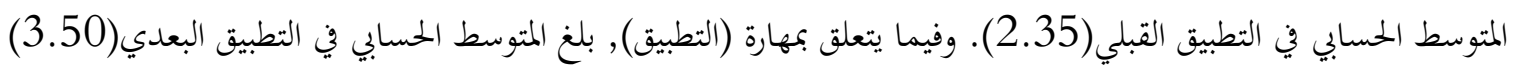

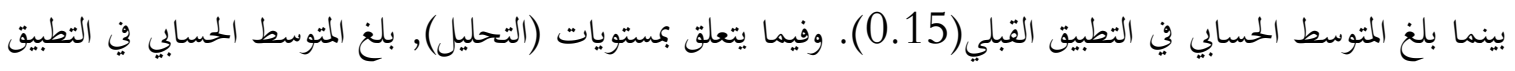

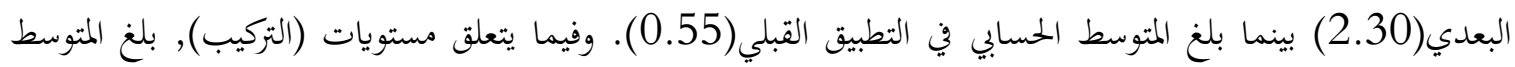

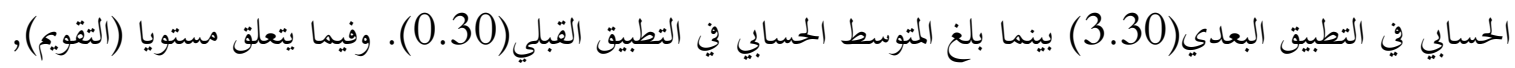

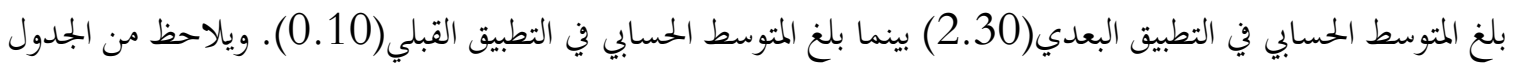

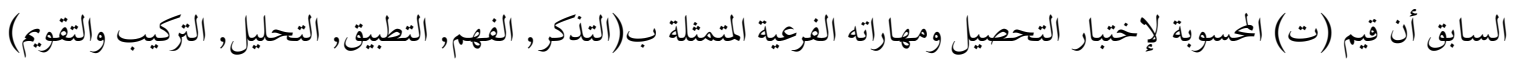

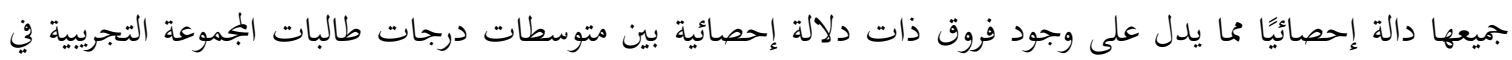

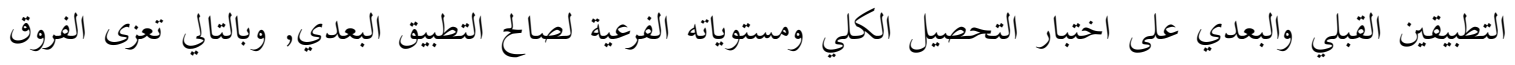




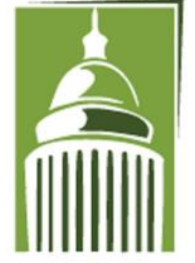

AR F

\section{Global Proceedings Repository}

American Research Foundation

ISSN 2476-017X
شبكة المؤمرات العربية

http://arab.kmshare.net/

Available online at http://proceedings.sriweb.org

للتدريس باستخدام البرنامج القائم على التعلم المدمج. ومن الجدول السابق يتضح أن نسبة الكسب المعدل لبلاك أكبر من الحد الفاصل الذي حدده بلاك والذي قيمته (1.2) مما يدل على ارتفاع فاعلية التدريس باستخدام البرنامج القائم على التعلم المدمج في تنمية هذه المستويات لدى الطالبات.

ويتبين من خلال النتائج السابقة التي توصلت إليها الباحثة أن لاستخدام البرنامج القائم على التعلم المدمج في تعليم الرياضيات فاعلية مقبولة وبتأثير مرتفع في تنمية التحصيل ومستوياته لدى طالبات الصف السابع الأساسي. وبذلك تتحقق صحة الفرض الثاني للبحث والذي نص على أنه: " يوجد فرق دال إحصائية بين متوسطي درجات

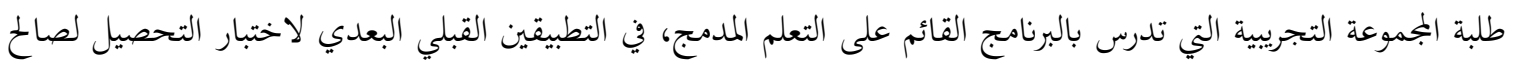

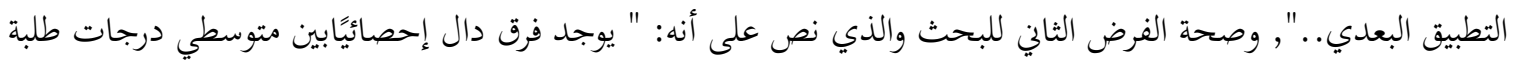
المجموعة الضابطة التي تدرس بالطريقة المعتادة وطلبة المجموعة التجريبية التي تدرس بالبرنامج القائم على التعلم المدمج، في لئي التطبيق البعدي لاختبار التحصيل لصالح طلبة المجموعة التجريبية، فقد تبين أن هناك فاعلية وأثر دال إحصائيًا لاستخدام البرنامج القائم على التعلم المدمج في تنمية التحصيل لدى طالبات المجموعة التجريبية. نتائج البحث: أسفر البحث عن النتائج التالية: 1. توجد فروق ذات دلالة إحصائية بين متوسطات درجات طالبات المجموعة التجريبية التي تدرس باستخدام البرنامج القائم على التعلم المدمج, في اختبار التحصيل الكلي للتطبيقين القبلي و البعدي, لصالح التطبيق البعدي. 2. توجد فروق ذات دلالة إحصائية بين متوسطات درجات طالبات المجموعتين الضابطة والتجريبية في اختبار التحصيل البعدي ككل, لصالح المجموعة التجريبية. توصيات البحث: توصي الباحثة بما يلي: توسينا 1. العمل على الاستفادة من البرنامج التعليمي القائم على التعلم المدمج, الذي اعدته الباحثة في تدريس مادة الرياضيات في المدارس. 2. عقد دورات تدريبية لمعلمي الرياضيات، أثناء الخحدة لتدريبهم على استخدام برامج تستند المى التعلم المدمج, بشكل يخدم العملية التعليمية بطريقة صحيحة وهادفة. 3. العمل على بناء برامج تعليمية وفقاً للتعلم المدمج, قي مباحث دراسية أخرى غير الرياضيات. 


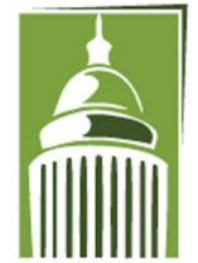

AR F

\section{Global Proceedings Repository}

American Research Foundation

ISSN 2476-017X

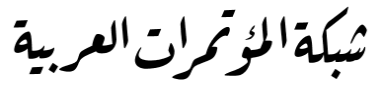

http://arab.kmshare.net/

Available online at http://proceedings.sriweb.org

$$
\text { مقتزحات البحث: }
$$

في ضوء ما سبق، تقترح الباحثة المجالات البحثية التالية:

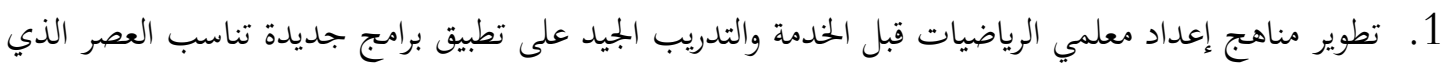

نعيش فيه.

2. تطوير برامج التنمية المهنية الخاصة بتطوير أداء معلمي الرياضيات أثناء الخدمة في ضوء التطورات العلمية والتربوية

الحديثة.

References : المراجع

اسماعيل، الغريب (2009). تكنولوجيا المعلومات وتحديث التعليم. القاهرة،عالم الكتب.

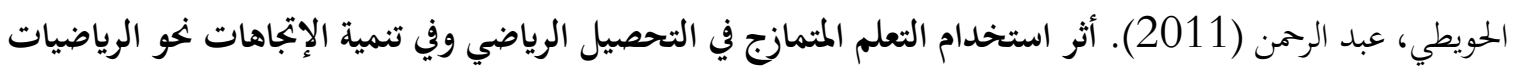

لدى طلاب الصف الرابع الإبتدائي في المملكة العربية السعودية. رسالة ماجستير، جامعة مؤته، عمان، الأردن.

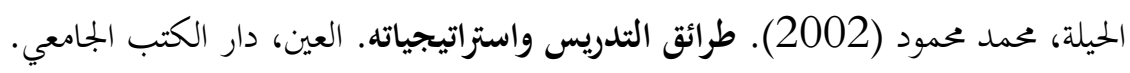

الجحلدي، عبد العزيز (2012). أثر استخدام التعلم الممدمج على تحصيل طالب الصف الأول المتوسط في الرياضيات واتجاهاتم نخوها. رسالة دكتوراه، جامعة أم القرى، المملكة العربية السعودية. الغامدي، خديجة (2009). التعلم المؤلف. مجلة العلوم الإنسانية. جامعة الملك سعود، السعودية.

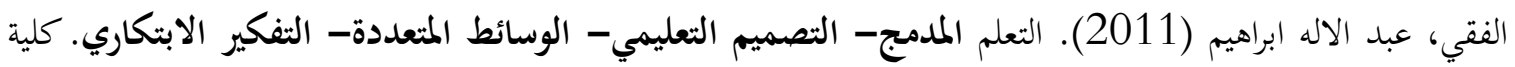

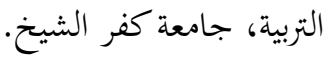

اللقاني،احد والجمل، علي (2003). معجم المصطلحات التربوية المعرفة في المناهج وطرق الثدريس. القاهرة، عالم

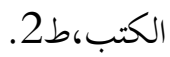

المعايطة، حمد (2006). أثر استخدام التعليم والتعلم المثمازج القائم على برنامج كورت لهندسة التفكير في تنمية مهارات الإتصال اللغوي لدى طلبة الجامعات الأردنية. الجامعة الأردنية، عمان. 


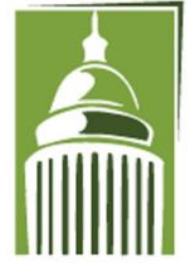

AR F

\section{Global Proceedings Repository}

American Research Foundation

ISSN 2476-017X

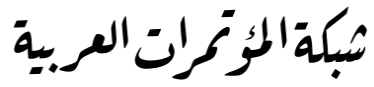

http://arab.kmshare.net/

Available online at http://proceedings.sriweb.org

الموسى، عبد الله والمبارك، أحمد (2005). التعليم الإلكتروني والأسس والتطبيقات. الرياض، مكتبة الرشيد.

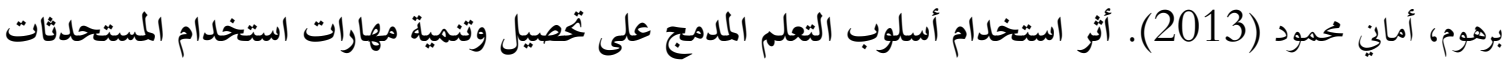

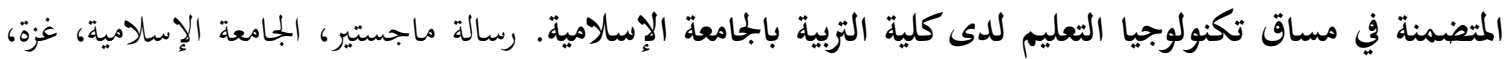
فلسطين.

بوشريخ، شاهر ذيب (2008). استراتيجيات الثدريس. عمان، المعتز للنشر والتوزيع.

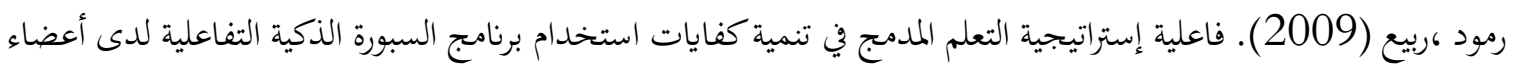
هيئة الثدريس بكلية التربية. المؤتمر العلمي الثاني عشر للجمعية المصرية لنكنولوجيا التعليم (تكنولوجيا التعلم الالكتروني

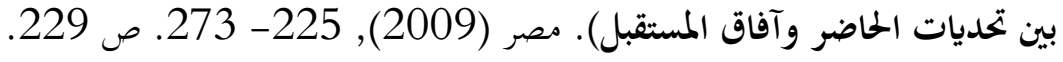
زيتون، حسن (2005). رؤية جديدة في التعليم والتعلم الالكتروني"المفهوم-القضايا-التطبيق-التقييم. الرياض، الدار الصوتية للتربية. سالم، أحمد (2009). تكنولوجيا التعليم والتعلم الإلكتووني. الرياض، مكتبة الرشيد.

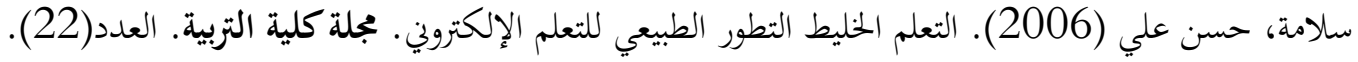
سيفين، عماد (2011م). التعليم والتعلم من النمطية إلى المملوماتية" رؤية عصرية في أساليب التدريس. القاهرة،عالم.

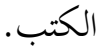
شوملي، قسطندي (2007). الأماط الحديثة في التعليم العالي والتعلم الالكتروفي المتعدد الوسائط او التعليم المتمانج.

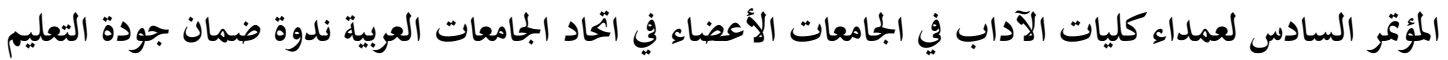

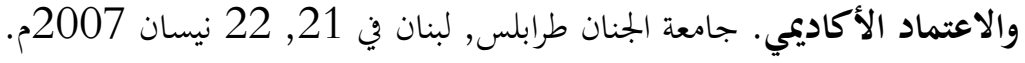

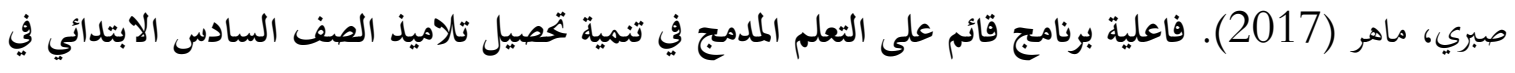

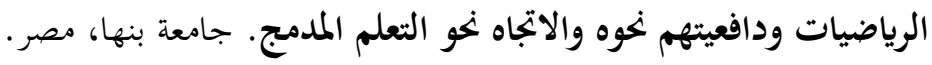

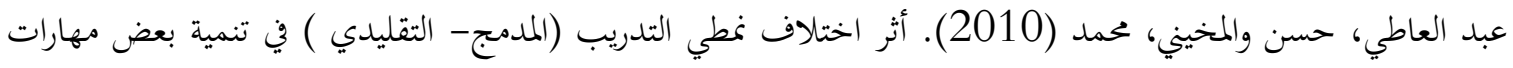

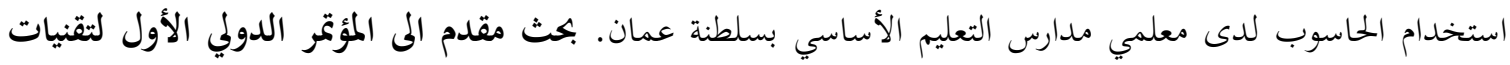
التعليم العالي. مسقط، سلطنة عمان. عطية، محمد خميس(2003). منتوجات تكنولوجيا التعليم. القاهرة، دار الكلمة. 


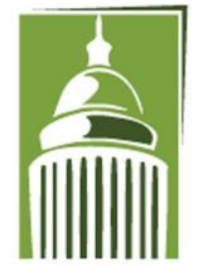

AR F
Global Proceedings Repository

American Research Foundation

ISSN 2476-017X

Available online at http://proceedings.sriweb.org

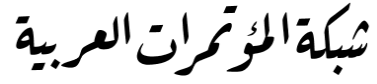

http://arab.kmshare.net/

علي، عادل (2012). فاعلية برنامج فائم على التعلم الملدمج في تنمية التحصيل والتفكير الابتكاري في الرياضيات لتلاميذ الصف السابع من مرحلة التعليم الأساسي بالجمهورية اليمنية. رسالة ماجستير، جامعة صنعاء، اليمن.

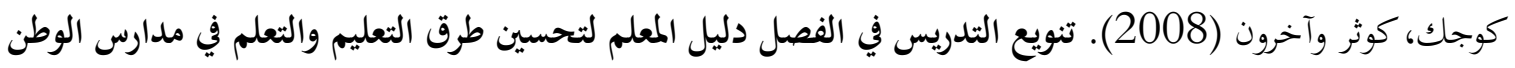
العربي. بيروت: مكتب اليونسكو الإقليمي للتربية في الدول العربية.

Balentye, P. \&Varga,M.A. (2016). The Effect of selfpaced blended learning of mathematics. Journal of Computers in Mathematics and Science Teaching, 35(3),201-223.

Bersin, B. (2005). Blended Learning: What work? (on line) available at:www.bersin.com

Eryilmaz, M. (2015). The effectiveness of blended learning environment. Contemporary Issues in Education Research (on line), 8(4), 225-251.

Haung. R, Zhou. Y(2005): Designing Blended Learning focused on knowledge Category and learning Activities Case studies from Beijing Normal university, Chapter Twenty - one, the book of blended learning, p,

Hudson, Brian (2005). Conditions for achieving communication, interaction and collaboration in E- learning.

Lin, Y. W., Tseng, C. L., \& Chiang, P. J. (2017). The effect of blended learning in mathematics course. Eurasia Journal of Mathematics, Science \& Technology Education, 13(3).

Office of Domestic Preparedness: ODP Approach for Blended Learning, 2003, Available at htt: //www. ojp. gov/blendedlearning. 15/2/2015

Thomson and Netg. (2005). The Next Generation of cooperate learning: Achieving the right Blended Learning Technology, Now Retieve from: (www.thomson.com). 